\title{
IMPACT OF SMARTPHONES, SELF-DETERMINATION AND PATIENCE ON SUBJECTIVE WELL-BEING OF BOTTOM OF PYRAMID CUSTOMERS
}

\author{
Fariha Reza \\ PhD Scholar \\ Shaheed Zulfikar Ali Bhutto Institute of Science and Technology - SZABIST \\ Karachi, Sind - Pakistan \\ Senior Lecturer \\ Institute of Business Management - IoBM \\ Karachi, Sind - Pakistan \\ fariharaza14@yahoo.com \\ Dr. Huma Amir \\ Assistant Professor \\ Institute of Business Administration - IBA \\ Karachi, Sind - Pakistan \\ hamir@iba.edu.pk \\ Dr. Syed Hasnain Alam Kazmi \\ Assistant Professor \\ Shaheed Zulfikar Ali Bhutto Institute of Science and Technology - SZABIST \\ Karachi, Sind - Pakistan \\ hasnain.kazmi@szabist.edu.pk
}

Study objective: This paper analyzes the impact of non-essential purchases, particularly smartphones, and patience on selfdetermination and subjective well-being of bottom of pyramid customers.

Method: 665 questionnaires were personally administered to respondents. Partial Least Squares Structural Equation Modelling (PLS SEM) was performed using SmartPLS software to test multiple dependency relationships between non-essential purchases, self-determination, subjective well-being and patience.

Main results: Non-essential purchases, particularly smartphones, had a direct effect on self-determination and an indirect effect on subjective well-being of bottom of pyramid customers. Non-essential purchases fulfilled psychological need for selfdetermination, that led to subjective well-being. Moreover, patience was established as a significant predictor of selfdetermination and subjective well-being.

Theoretical/ methodological contributions: This paper makes a theoretical contribution by connecting social identity theory, self-determination theory and patience with non-essential purchases and subjective well-being of bottom of pyramid customers.

Relevance/ originality: Relatively fewer researches are available in Western marketing literature that connect patience with selfdetermination and subjective well-being of bottom of pyramid customers. The novel insight of this research showed that nonessential purchases can restore a sense of subjective well-being in such customers and when poverty related adverse situations tend to lower subjective well-being of these customers, patience positively impacts their self-determination and does not let them despair.

Managerial and social implications: Marketers can use the insights from this research to develop products that satisfy bottom of pyramid customer's psychological needs for self-determination that lead to subjective wellbeing in a consumer society.

Keywords: Non-essential purchases. Bottom of pyramid. Self-determination. Subjective well-being. Patience.

How to cite the article

American Psychological Association (APA)

Reza, F., Amir, H., \& Kazmi, S. H. A. (2021, Apr./June). Impact of smartphones, self-determination and patience on subjective well-being of bottom of pyramid customers. Brazilian Journal of Marketing, 20(2), 279-308. https://doi.org/10.5585/remark.v20i2.17569. 


\section{Introduction}

Bottom of Pyramid (BoP) is a demographic segment that comprises of economically challenged persons. World Bank defines BoP as a set of people who are living on less than USD 2 per day whereas, United Nations Development Program (UNDP), describes BoP as those who are living on less than USD 8 per day (United Nations Development Programme [UNDP], 2008; World Bank Development Research Group, 2017). Consumer society describes poverty in terms of consumption inadequacy - a failure to engage in socially relevant consumption practices (Martin \& Hill, 2015). Therefore, at times, a person who is above the stark starvation point may still be included in BoP segment because of his or her inability to meet decent living conditions. Consumer research has focused on people living beyond USD 10 per day, who have expereinced social exclusion on account of their consumption inadequacy, as the subject of their BoP research (Yurdakul, Atik, \& Dholakia, 2017). Hence, BoP becomes a multifaceted issue that is relevant to context, culture and time (Chmielewski, Dembek, \& Beckett, 2018). Therefore, marketing literature is forwarding the debate that BoP should be defined through broader concepts that take into account resources, capabilities, relations, and desires (Yurdakul, Atik, \& Dholakia, 2017).

Extant literature identifies items other than food, clothing, and education as nonessential purchases (Hill, 2018). Non-essential purchases are also called material purchases or discretionary purchases that are made for enjoyment, pleasure, or stimulation and not for day to day survival (Brown, Kasser, Ryan, \& Konow, 2016). In a consumer society, poverty is seen as being unable to engage in socially relevant consumption practices. People who are consumption-inadequate due to economic constraints are negatively stereotyped as flawed persons and are socially excluded by those who are better off (Hamilton, et al., 2014). Such negative stereotyping induces poverty-related shame and erodes dignity and self-respect of economically challenged people (Blocker, et al., 2013). At times, such people make nonessential purchases to improve their self-worth and reflect an improved social status (Yurdakul, Atik, \& Dholakia, 2017). In a digitized world, intensive and extensive digital technology usage is also a part of socially relevant consumption practices that are assumed to reflect an improved social status. Therefore, economically challenged persons who want to emulate a better lifestyle strive to access and use internet in their everyday lives (Pearce \& Rice, 2013). BoP customers who strongly feel social exclusion, are more inclined to use technology and devices to experience social inclusion (Baishya \& Samalia, 2020). Among all the devices and systems that 
make up digital technology, smartphones are widely used by the poor across the world as an antidote to poverty-related shame and exclusion (Prahalad, 2019). Therefore, for this research, smartphone was considered as an apt example of a non-essential purchase that reflects technology based aspirational consumption in BoP segments (Baishya \& Samalia, 2020).

This research aims to establish the impact of non-essential purchases (in particular smartphones) and self-determination on BoP customers' subjective well-being. It combines social identity theory and self-determination theory to determine the mediating impact of selfdetermination on the relationship between intention to purchase smartphones and subjective well-being. Social identity theory posits that identity of a person is group-based and is revealed through cognitive, attitudinal, or behavioral outcomes (Stets \& Serpe, 2013). Social stereotyping is an example of cognitive outcome, whereas evaluating a group favorably is an attitudinal outcome, and behaving according to group norms is an example of behavioral outcome. In consumer culture, bottom of pyramid customers are negatively stereotyped as flawed and frustrated customers because of their consumption inadequacy (Martin \& Hill, 2012). BoP customers create different groups based on their consumption patterns and classify consumption-inadequate as poor and consumption-adequate as rich. BoP customers aspire to be more like the rich and experience social inclusion through purchases that reflect their improved financial status. Therefore, non-essential purchases are seen in the theoretical frame of social identity theory as a means to mitigate the ill effects of negative stereotyping of $\mathrm{BoP}$ customers.

Self-determination theory relates personality, motivation and optimal functioning of people (Ryan \& Deci, 2000). The basic premise of this theory is that motivation is either intrinsic or extrinsic, and when it combines with external factors, it drives a person to fulfil the need for autonomy, competence, and relatedness (Ryan \& Deci, 2000). Therefore, while it was suggested that multidimensional deprivations will decrease subjective well-being, Martin and Hill (2012) suggested that if the psychological needs of autonomy, competency, and relatedness are fulfilled, the negative impact of impoverishment on subjective well-being may be reduced (Martin \& Hill, 2012; Cannon, Goldsmith, \& Roux, 2019).

Conumer research has studied well-being as an outcome of market exchange relationship focusing on middle and upper socio-economic segments, however, the psychological outcome associated with consumption for BoP consumers is still elusive (Martin \& Hill, 2012). Therefore, this research studies how non-essential products improve the 
subjective well-being of BoP customers who are often negatively sterotyped as unhappy customers.

Besides studying the relationship between non-essential purchases, self-determination and subjective well-being, this study also aims to determine the impact of patience on subjective well-being of BoP customers in the context of adversity. Patience is an under-researched area in Western marketing literature (Haybron, 2016); therefore, studying its impact on selfdetermination and subjective well-being of BoP customers adds value to existing literature. BoP customers are an intriguing population because, despite facing economic constraints, they purchase aspirational products too, and at times they trade off their necessities for such purchases (Atkin, Colson-Sihra, \& Shayo, 2019). Although more affluent persons also make trade-offs between necessary and non-essential items, it is interesting to study this phenomenon in BoP customers because of the critical nature of the trade-off itself.

\section{Non-essential purchases and subjective well-being}

Subjective well-being defines how happy and satisfied a person is with his or her life as a whole (Diener, Oishi, \& Lucas, 2015). Happiness is a short term state factor, whereas satisfaction is a long-term trait factor (Martin \& Hill, 2015). In other words, happiness is a state of momentary joy and pleasure, whereas satisfaction is a trait of contentment. The ideology of consumer culture emphasizes happiness and contentment through consumption (Jafari, Dedeoğlu, Regany, Üstündağli, \& Batat, 2014). That is to say that the more a person can afford and purchase, the happier and contented they are. Weak purchasing power leads to inadequacies in consumption that separate consumption-poor people from those who can afford and access socially relevant products and services. The society stereotypes such people as frustrated, flawed, and unhappy (Hamilton, et al., 2014). Moreover, this stereotyping results in social exclusion of the poor and an increase in their felt poverty (Chikweche \& Fletcher, 2012).

Social identity theory explains this phenomenon. It states that individuals identify ingroups and out-groups in a structured society and understand their belongingness to a particular group based on social comparisons (Stets \& Serpe, 2013). Individuals make intergroup comparisons whose outcomes bring a level of satisfaction or dissatisfaction with their current social identity. Such social comparisons are compelling for those who want betterment in their lives (Hill, Martin, \& Chaplin, 2012).

In light of social comparisons, it is essential to realize that consumption-inadequate people are often stigmatized with negative social evaluations and are subject to derogatory 
behavior because they are unable to become a part of consumer culture (Adkins \& Ozanne, 2005; Garrette \& Karnani, 2010). Under such circumstances, externally referenced reasons, such as being looked down upon by others, combine with partially internalized values, such as enhancing self-dignity, to create controlled motivation that makes a person engage in compensatory buying behavior (Dahana, Kobayashi, \& Ebisuya, 2018). Extant literature suggests that controlled motivation, such as avoidance of poverty-related stereotyping, to project an enhanced financial status, and to socialize with people belonging to one's aspirational groups, increases the desire to purchase discretionary products, resulting in subjective wellbeing (Dahana, Kobayashi, \& Ebisuya, 2018; Gupta \& Srivastav, 2015; Martin \& Hill, 2015; Yurdakul, Atik, \& Dholakia, 2017).

Previous researches have shown that consumption-inadequate consumers make hedonic purchases to transform their lives and feel happiness (Alba \& Williams, 2013; Gupta \& Srivastav, 2015). Such studies have focused on the retrospective evaluation of past purchases and their relationship with well-being. Since buying is a continuous process, an anticipation of purchase also evokes positive emotions, however, relatively fewer researches have focused on the relationship between purchase intentions and well-being (Moldes, Banerjee, Easterbrook, Harris, \& Dittmar, 2019). In separate studies, intention to shop and intention to participate in online shopping carnivals were seen as a predictors of consumer well-being for segments other than BoP (Papagiannidis, Bourlakis, Alamanos, \& Dennis, 2017; Yu, Zhang, \& Liu, 2018). Although economically challenged customers engage in materialistic purchases to feel happy, studies suggest that the impact of such purchases on well-being needs to be further explored (Moldes, Banerjee, Easterbrook, Harris, \& Dittmar, 2019). Therefore, this research studies the relationship between intention to purchase non-essential items that enhance self-concept and subjective well-being. An apt example of such a product is smartphone which is rapidly pentrating BoP population as it tends to provide an antidote to poverty related stereotyping and increase well-being (Baishya \& Samalia, 2020; Prahalad, 2019). Therefore, it is hypothesized:

H1: Intention to purchase smartphone (ITP) has a positive impact on subjective wellbeing (SWB) of BoP customer.

\subsection{Non-essential purchases and self-determination}

As explained above, a person's happiness level would be low if he or she experiences poverty-induced shame and social exclusion. However, the relationship between poverty and subjective well-being is influenced by self-determination which manifests itself through 
autonomy, relatedness, and competence (Martin \& Hill, 2012). This is explained through selfdetermination theory which relates personality, motivation and optimal functioning of people (Ryan \& Deci, 2000). The basic premise of this theory is that motivation is either intrinsic or extrinsic, and when it combines with external factors, it drives a person to fulfil the need for autonomy, competence, and relatedness (Ryan \& Deci, 2000). Therefore, while it was suggested that multidimensional deprivations will decrease subjective well-being, Martin and Hill (2012) suggested that if the psychological needs of autonomy, competency, and relatedness are fulfilled, the negative impact of impoverishment on subjective well-being may be reduced (Cannon, Goldsmith, \& Roux, 2019; Martin \& Hill, 2012). That is to say that when life situations offer limited choices, a person would experience loss of control, lower confidence and lower sense of relatedness to others, and would be less happy and satisfied with life; however, when these psychological needs of autonomy, relatedness and confidence are met, a person's level of happiness and satisfaction would increase. Therefore, recent research suggests that researchers may study aspirational consumption at the bottom of the pyramid from the perspective of self-determination theory (Srivastava, Mukherjee, \& Jebarajakirthy, 2020). Consequently, this research focuses on the impact of intention to purchase non-essential products on self-determination and subjective well-being. This objective leads to the following hypotheses:

H2: Intention to purchase smartphone (ITP) has a positive impact on self-determination (SD) of BoP customer

H3: Self-determination (SD) has a positive impact on subjective well-being (SWB) of BoP customer

While earlier research shows that a person may seek happiness from material purchases that reflect financial status, self-determination theory says that psychological needs of autonomy, relatedness and competence should be met before happiness can be experienced (Chen, Yao, \& Yan, 2014; Yu, Levesque-Bristol, \& Maeda, 2017). In other words, selfdetermination mediates the relationship between materialism and subjective well-being (Wang, Liu, Jiang, \& Song, 2017). Based on these previous findings, the following hypothesis was developed to study the mediating role of self-determination: 
H4: Self-determination (SD) mediates the relationship between intention to purchase smartphone (ITP) and subjective well-being (SWB) for BoP customers

Connecting Patience with Self-determination and Subjective Well-being for BoP Customers

Patience is typically defined as remaining calm in the face of frustration and adversity (Schnitker, 2012). Western world has largely remained silent on patience because people belonging to Western culture want to avoid suffering, which makes a person aware of his or her incapacity (Haybron, 2016). However, in the context of BoP, where poor people suffer from poverty-related negative stereotyping, patience becomes a relevant topic of research. As discussed next, despite a few studies on patience, researchers have not reached a consensus on the nature of this construct. Therefore, a brief discussion of this construct shows how researchers approach the subject of patience.

Patience has been defined in multiple ways by researchers in the realm of theology, philosophy, psychology, and psychology of religion (Bülbül \& Arslan, 2017; Schnitker, Houltberg, Dyrness, \& Redmond, 2017). It has been identified as a value, a virtue, and a personality trait in existing literature (Schnitker, Houltberg, Dyrness, \& Redmond, 2017). It has been described as an acquired disposition as well as a behavioral state. This research studies patience as a personality construct related to effective emotion regulation that provides a buffer against stressful emotions (Bülbül \& Arslan, 2017).

While patience is remaining calm and showing tolerance in adverse situations, selfdetermination is a person's self-awareness about the extent of control, competence and social connectedness. In other words, patience is reflected through a person's control over emotions and self-determination is manifested through control over one's circumstances, competence, and connectedness with others. Both patience and self-determination include control over one's emotions or circumstances, therefore, Bulbul and Arslan (2017) suggested that selfdetermination and patience are positively correlated. In this research, patience was studied as a predictor of self-determination, leading to the following hypothesis:

\section{H5: Patience has a positive impact on self-determination (SD) of BoP customers}

Earlier research showed that patience influenced a person's pursuit of goals and that affected well-being (Schnitker, Houltberg, Dyrness, \& Redmond, 2017). In other words, patience increased hedonic well-being through increased goal achievement, therefore, this 
research studied the impact of patience on self-determination and subjective well-being of customers and the mediating role of self-determination on the relationship between patience and subjective well-being. Mediation analysis studies the direct and indirect effects of one factor on another factor, therefore, the mediation effect was tested through following hypotheses:

H6: Patience has a direct impact on subjective well-being (SWB) of BoP customers.

H7: Self-determination (SD) mediates the relationship between patience and subjective well-being (SWB) of BoP customers

The central issue of this paper is to study the relationship between intention to purchase smartphone and subjective well-being in BoP context. Traditionally, consumer research has studied well-being as a consequence of consumer purchases, focusing more on affluent customers rather than BoP customers because of the weak purchasing power of the latter (Alba $\&$ Williams, 2013). Literature suggests that negative stereotyping of the poor makes them aspire for products that signal status, improve their self-worth, and help them in gaining inclusion in their aspirational groups. Literature also suggests that ill-effects of poverty decrease the subjective well-being of individuals, however, if self-determination needs are fulfilled, the impact of poverty on subjective wellbeing is mitigated (Martin \& Hill, 2015). Therefore, this paper studies the mediating role of self-determination on the intention to purchase products that reflect an improved status and enhance self-worth and subjective well-being of BoP customers by connecting self-identity theory with self-determination theory. These theories were extended by the addition of the new construct, patience, that affects self-determination as well as subjective well-being of BoP customers (Schnitker, Houltberg, Dyrness, \& Redmond, 2017).

The conceptual model in figure 1 shows the relationship between intention to purchase, self-determination, subjective well-being, and patience. 
Figure 1: Theoretical Model

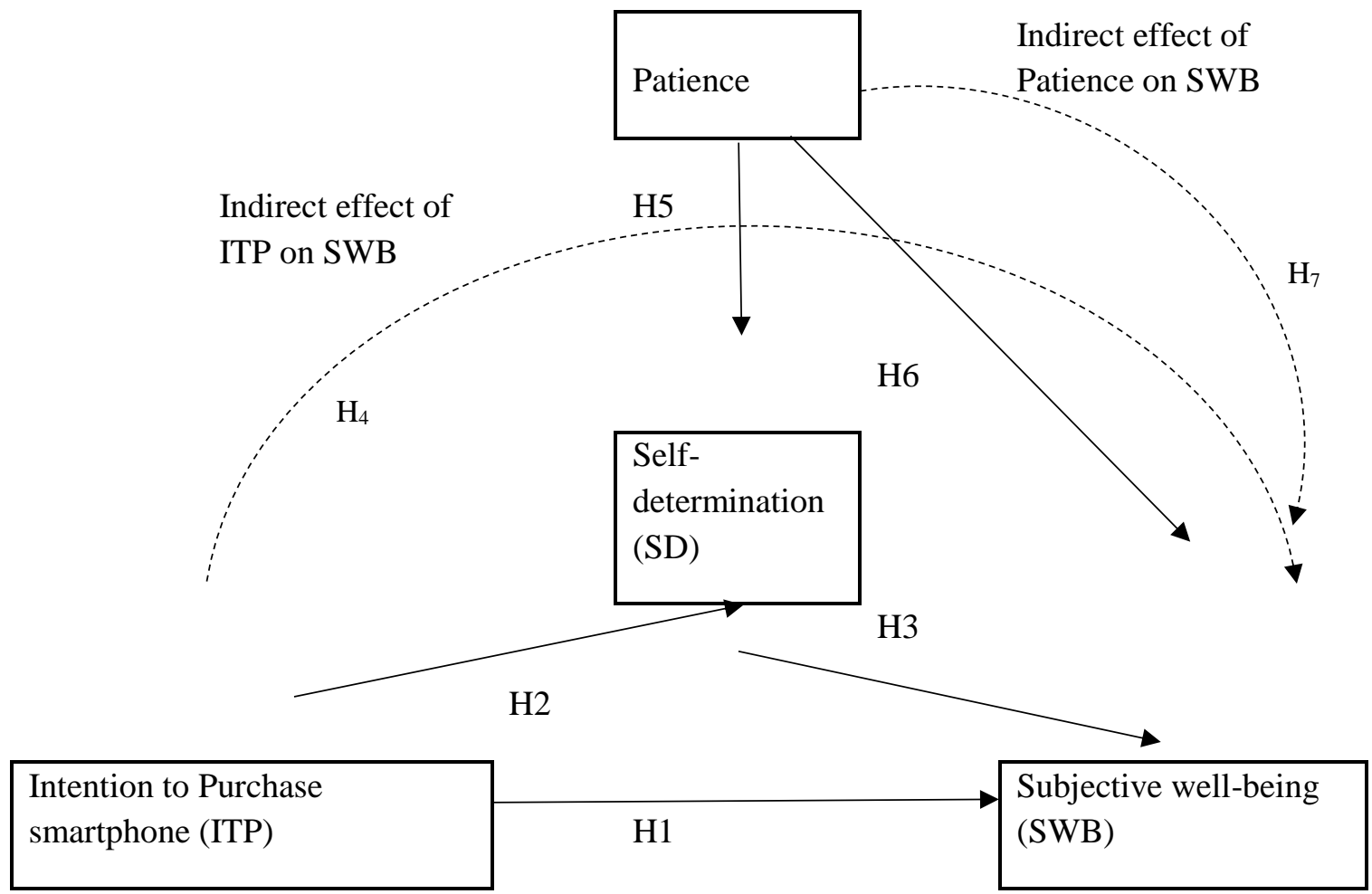

Source: Literature review for this research.

\section{Methodology}

This study aimed to analyze the multiple dependency relationships between intention to purchase smartphone, self-determination, patience, and subjective well-being of BoP customers. These multiple dependency relationships were tested through PLS analysis using SmartPLS software because of its user-friendliness and ability to accommodate non-normality, multicollinearity, and missing values in the given data set. Traditionally, mediation has been tested in SPSS using PROCESS approach, however, it is more advantageous to use PLS-SEM mediation analysis because the pre-condition of normal distribution is not required in PLS-SEM approach (Hair, Sarstedt, Hopkins, \& Kuppelwieser, 2014). Furthermore, mediation analysis 
using PLS-SEM yields higher statistical power in comparison with Sobel test (Matthews, Hair, $\&$ Matthews, 2018). Therefore, for these reasons, the researchers used mediation analysis using PLS-SEM approach in SmartPLS.

\subsection{Population and sampling}

From the multiple economic definitions of BoP, this research used UNDP's criteria of living on less than USD 8 per day - equivalent to approximately Pakistani Rupee (PKR) 40,000 per month - to identify the BoP population (UNDP, 2008). This definition enabled the researchers to focus on those $\mathrm{BoP}$ customers who were not dependent on welfare programs for their basic survival, and somehow purchased non-essential products occasionally (Hill, Martin, $\&$ Chaplin, 2012). Furthermore, in the context of digital influence on the lives of BoP, people who owned smartphones despite earning less than USD 8 per day were the relevant population for this research. Therefore, males and females aged between 18-55 years, residing in Karachi, earning less than USD 8 per day, and possessing smartphones, were considered as the population for this research (Alkire \& Santos, 2014; Hamilton, et al., 2014; UNDP, 2008).

Pakistan was considered a research-worthy setting for this research because $63 \%$ of its total population is experiencing multidimensional poverty. Furthermore, the level of multidimensional poverty in urban areas is $32 \%$, and for rural areas, $81 \%$ (Javed \& Awan, 2020). This setting also provided an opportunity to study technology's influence because mobile penetration is $76 \%$, mobile internet penetration is $21.3 \%$, and $31 \%$ of adults are smartphone users in Pakistan (Farooq, 2019). From the aspect of a digital revolution, the number of smartphone connections in Pakistan is 56 million, constituting 33\% of the total number of mobile connections. The Government of Pakistan is actively promoting efforts to manufacture handsets locally, and nearly 9 million devices have been produced locally since 2016 (Okeleke, 2019). Furthermore, the sale and purchase of used cell phones are also allowed in Pakistan, making cell phone ownership possible for the poor. Similarly, economical network services packages are also facilitating the use of internet through mobile phones for poor customers. Therefore, owning a cell phone itself is one of the widely observed phenomenon among the poor in Pakistan (Butt, 2020).

Karachi's population is approximately $17,636,000$ and consists of people belonging to diverse backgrounds, such as (but not limited to) different communities, cultures, ethnic backgrounds, social backgrounds, and occupations. This diversity makes Karachi a judicious 
sample of Pakistan's BoP that has experienced discretionary purchase decisions and technological influence (Mitlin \& Satterthwaite, 2012; World population review, 2017).

Gamma-exponential method suggests a sample size of 619 for PLS models for which the margin of error is $5 \%$, and statistical power is $85 \%$ (Kock \& Hadaya, 2016). Previous researches on BoP have found 600 sample size as adequate; therefore, a sample size of 665 for this research was sufficient to proceed with data analysis (Sharma \& Nasreen, 2017). Chainreferral method was used in this research to select sample subjects. Sampling was respondentdriven, in which early respondents recruited additional respondents. Early respondents were compensated for their participation in recruitment. This method overcame the problems of inaccessibility and mistrust in the targeted population (Alexander \& Prasad, 2014).

\subsection{Process of developing questionnaire}

A structured questionnaire was designed using well-established scales that measured intention to purchase non-essential items (specifically a smartphone), self-determination, patience, and subjective well-being. Martin and Hill (2012) used the self-determination scale that measured psychological needs for autonomy, relatedness to others, and competence, which was adopted in this research. This research studied two dimensions of subjective well-being, namely, happiness and satisfaction with life. Happiness was measured using the scale given by Richins (2004) whereas satisfaction with life was measured by the scale given by Diener, Emmons, Larsen, and Griffin (1985). Similarly, patience was measured by adopting a scale used in earlier researches that measured interpersonal patience, life hardship patience, and daily hassle patience (Schnitker, 2012). The response format for 79 scale items used in the questionnaire was a 5-point Likert scale (Zikmund, Babin, Carr, \& Griffin, 2013). The 5-point itemized rating scale was used because in the context of BoP, where linguistic proficiency is affected by low education levels, increasing the number of response category may not improve scale sensitivity (Pathak, et al., 2020).

Since the targeted population was not proficient in English, the original questionnaire was translated into Urdu language commonly understood by the population. The original scale items were translated linguistically, and word choice was refined to suit the culture of the targeted population (Beaton, Bombardier, Guillemin, \& Ferraz, 2000). Back translation established translation adequacy (Epstein, Santo, \& Guillemin, 2015). At this stage, face validity was determined by seeking expert advice of two professionals involved in practicing and teaching marketing research. This process established that the tool was fit for pilot testing. 
The questionnaire's translation adequacy and appropriateness were further established through pilot testing (Epstein, Santo, \& Guillemin, 2015). Translated questionnaire was used in pilot survey to uncover any problems related to questionnaire design, sampling technique, and data analysis. A few scale items were improved further by using words from everyday language suggested by respondents (Beaton, Bombardier, Guillemin, \& Ferraz, 2000). One such example was the word 'satisfaction'; its original translation was replaced by a simpler word to make the question easy to comprehend.

The questionnaire used in pilot testing included 105 scale items. These were reduced to 79 items by deleting items scale-wise to improve reliability statistics. For example, the original questionnaire used 13 items to measure subjective wellbeing. The reliability of these of this scale was .583 . Reliability statistics of this scale were improved to .711 after removing 5 items from the scale using the option 'Alpha with item deleted' in SPSS (Cho \& Kim, 2014; Greco, O'Boyle, Cockburn, \& Yuan, 2017). Shows that all the scales used in the final questionnaire were valid and reliable (Cronbach's alpha>.7).

Table 1 - Reliability statistics

\begin{tabular}{lll}
\hline \multicolumn{1}{c}{ Scale } & No. of items & $\begin{array}{c}\text { Cronbach's } \\
\text { alpha }\end{array}$ \\
\hline ITP & 6 & .882 \\
SD & 6 & .865 \\
SWB & 10 & .711 \\
Patience & 9 & .706 \\
\hline Source: SmartPLS output of research data for this research.
\end{tabular}

\section{Results}

\subsection{Goodness of fit of measurement model}

In the reflective measurement model shown in figure 2 , intention to purchase smartphone (ITP) and Patience were exogenous variables, while self-determination (SD), and subjective well-being (SWB) were endogenous variables. 
Figure 2: Adjusted model after dropping weak indicato

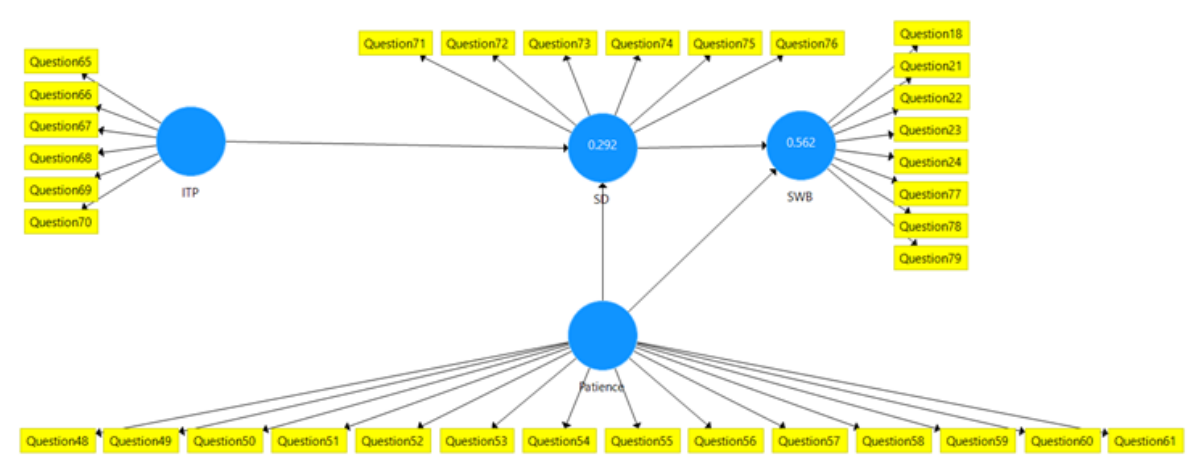

Source: Research data.

\subsubsection{Convergent and composite reliability}

Outer model loadings represent inter-item reliability, and their values range from 0 to 1 because SmartPLS automatically standardizes the data before calculating loadings (Garson, 2016; Hair, Black, Babin, Anderson, \& Tatham, 2006). The closer the value of loading is to 1, the stronger and more reliable is the measurement model; the closer this value is to 0 , the weaker and less reliable is the measurement model. Literature supports exclusion of indicators with path loadings less than 0.4 if their deletion improves composite reliability of the model (Hair, Black, Babin, Anderson, \& Tatham, 2006). Therefore, in this research, weak indicators of SWB were removed from the model. Hence, items such as question 19, with outer loading .072, were removed to improve the composite reliability of all the constructs (Garson, 2016; Ringle, Silva, \& Bido, 2015). Justification for scale purification was driven by reliability, validity and parsimony considerations, and was based on both statistical and judgmental criteria (Wieland, Durach, Kembro, \& Treiblmaier, 2017).

After dropping weak indicators, composite reliability for all constructs in the model became greater than 0.6 ; hence, the convergent reliability was considered satisfactory (Henseler, Fassott, Dijkstra, \& Wilson, 2012). Another measure of internal reliability is Cronbach's alpha. It is a conservative measure of reliability, and a value of 0.6 or higher is adequate for an exploratory purpose (Garson, 2016). Cronbach's alpha for the constructs was also higher than 0.6 . in this research showing that internal reliability was also satisfactory.

Average Variance Extracted (AVE) is another goodness of fit measure that reflects convergent validity. It determines the average communality for each latent factor. In other words, it is the average of factorial loadings squared (Ringle, Silva, \& Bido, 2015). It is 
recommended that AVE value be equal to or greater than 0.5 , that is, factors should explain at least $50 \%$ of the variance of their indicators. However, if AVE is less than 0.5 , but composite reliability is greater than 0.6 , convergent validity of the construct is still adequate (Fornell \& Larcker, 1981; Ringle, Silva, \& Bido, 2015). It is recommended that AVE value be equal to or greater than 0.5 , that is, factors should explain at least $50 \%$ of the variance of their indicators. However, if AVE is less than 0.5, but composite reliability is greater than 0.6, convergent validity of the construct is still adequate (Fornell \& Larcker, 1981; Ringle, Silva, \& Bido, 2015). Since composite reliability of the constructs was greater than 0.6 , the latent constructs' convergent validity in this research was still considered as adequate despite AVE being less than 0.5 . Reliability and convergent validity statistics for constructs of the adjusted model are presented in Erro! Fonte de referência não encontrada.

Table 2: Convergent and composite reliability

\begin{tabular}{llll}
\hline Construct & $\begin{array}{c}\text { Cronbach's } \\
\text { alpha }\end{array}$ & $\begin{array}{c}\text { Composite } \\
\text { reliability }\end{array}$ & $\begin{array}{c}\text { Average variance } \\
\text { extracted (AVE) }\end{array}$ \\
\hline ITP & 0.838 & 0.834 & 0.463 \\
Patience & 0.787 & 0.730 & 0.190 \\
SD & 0.697 & 0.692 & 0.275 \\
SWB & 0.617 & 0.612 & 0.181
\end{tabular}

Source: SmartPLS output of research data for this research.

\subsubsection{Divergent validity}

Divergent validity, also called discriminant validity, is the extent to which a construct is truly distinct from other constructs, that is to say, it is the extent to which a construct correlates with other constructs and the extent to which its measured variables load only on that construct (Hair, Gabriel, \& Patel, 2014). One of the preferred measures of divergent validity is the hetrotrait-monotrait (HTMT) ratio, in which correlations of indicators across constructs are divided by the correlations of the indicators within the constructs (Sarstedt, Ringle, \& Hair, 2017). Divergent validity exists if hetrotrait correlations are less than monotrait correlations, that is to say that the ratio of hetrotrait correlation to monotrait correlation is less than 1 (Garson, 2016). Discriminant validity is adequate if this ratio is less than 0.9 (Sarstedt, Ringle, \& Hair, 
2017). HTMT ratio for latent constructs presented in Table 3 shows that divergent validity of these constructs was adequate as all values were below 0.9 .

Table 3 - Divergent validity

\begin{tabular}{lrll}
\hline \multicolumn{1}{c}{ Construct } & ITP & Patience & SD \\
\hline Patience & 0.172 & & \\
SD & 0.441 & 0.366 & \\
SWB & 0.458 & 0.396 & 0.720 \\
\hline
\end{tabular}

Source: SmartPLS output of research data for this research.

\subsubsection{Bootstrapped significance of outer loadings}

The bootstrap algorithm computes significance for outer loadings, path coefficients, indirect effects, direct effects, and total effects (Garson, 2016). This algorithm produces a path diagram that shows t-test values on the connectors; all t-test values greater than 1.96 are significant. All outer loadings of the adjusted model were significant $(\mathrm{p}<.05)$.

The convergent reliability, divergent reliability, and bootstrapped significance of outer loadings determined that the fitness of measurement model was acceptable to proceed with the assessment of structural model fit.

\subsection{Goodness of Fit for Structural Model}

Goodness of fit for structural model measures the strength of direct and indirect effects of one latent variable on another. Structural path coefficients, R-Square value, and multicollinearity determine the validity and reliability of the inner model (Garson, 2016).

\subsubsection{Magnitude and significance of direct effects}

Structural path coefficients are the standardized regression coefficients of paths that connect latent variables, and their value varies between 0 and 1 (Hair, Black, Babin, Anderson, \& Tatham, 2006). Larger values of path coefficients show stronger effects between latent variables (Garson, 2016). Direct effects are the standardized path coefficients between an exogenous and an endogenous variable. Direct path coefficients for the adjusted model are shown in Table 4. The impact of ITP on SD, Patience on SD, and SD on SWB, are strong (coefficient >.26\%); however, the impact of Patience on SWB is moderately strong $(.13<$ coefficient<.26) (Ringle, Silva, \& Bido, 2015). 
Table 4 - Magnitude of Direct Effects

\begin{tabular}{lcc}
\hline \multicolumn{1}{c}{ Construct } & SD & SWB \\
\hline ITP & 0.403 & \\
Patience & 0.302 & 0.145 \\
SD & & 0.684
\end{tabular}

Source: SmartPLS output of research data for this research.

Significance of PLS path coefficients is computed with bootstrapping through resampling methods (Garson, 2016). Table 5 shows that the direct effects between all the latent variables in the structural model are significant at alpha 0.05 . The significance of t-statistics concluded that all direct effects shown in the adjusted model were significant.

Table 5 - Bootstrapped Significance of Direct Effects

\begin{tabular}{llllll}
\hline \multicolumn{1}{c}{ Direct Path } & $\begin{array}{c}\text { Original } \\
\text { sample (O) }\end{array}$ & $\begin{array}{c}\text { Sample } \\
\text { mean }(\mathbf{M})\end{array}$ & $\begin{array}{c}\text { Standard } \\
\text { deviation } \\
(\mathbf{S T D E V})\end{array}$ & $\begin{array}{c}\text { t-statistics } \\
(|\mathbf{O} / \mathbf{S T D E V}|)\end{array}$ & p-values \\
\hline ITP -> SD & 0.317 & 0.320 & 0.035 & 9.076 & 0.000 \\
$\begin{array}{l}\text { Patience -> } \\
\text { SD }\end{array}$ & 0.231 & 0.239 & 0.043 & 5.363 & 0.000 \\
$\begin{array}{l}\text { Patience -> } \\
\text { SWB }\end{array}$ & 0.161 & 0.168 & 0.041 & 3.933 & 0.000 \\
SD -> SWB & 0.453 & 0.456 & 0.037 & 12.291 & 0.000 \\
\hline
\end{tabular}

Source: SmartPLS output of research data for this research

\subsubsection{Magnitude and significance of indirect effects}

Indirect effects show the effect of a latent variable on an endogenous variable that is mediated by one or more additional latent variables (Garson, 2016). An indirect effect is the multiplicative effect of the path coefficients between indirectly connected constructs. For example, in the adjusted model shown in figure 2, the indirect effect of Patience on SWB is the product of the direct path coefficient between Patience and SD, 0.302, and the direct path coefficient between SD and SWB, 0.684, giving an indirect effect of 0.207. Similarly, the 
indirect effect of ITP on SWB is 0.276. Bootstrapping output in Table 6 shows that indirect effects between latent variables as well as specific indirect paths were significant $(p<.5)$. Hence, ITP has a strong and significant indirect effect on SWB (coefficient>.26) and Patience has a moderately strong and significant indirect effect on SWB (.13<coefficient<.26) (Ringle, Silva, \& Bido, 2015).

Table 6: Magnitude and Significance of Indirect Effects

\begin{tabular}{lll}
\hline \multicolumn{1}{c}{ Indirect path } & Indirect effect & p- values \\
\hline ITP -> SWB & .276 & 0.000 \\
Patience -> & .207 & 0.000 \\
SWB & &
\end{tabular}

Source: SmartPLS output of research data for this research.

\subsubsection{Assessing model fit through R-square}

$\mathrm{R} 2$, also known as the coefficient of determination, determines the extent to which the predictor variables explain the variation in the endogenous variable. The value of R2 ranges from 0 to 1, and the higher the value, the better is the model (Sekaran \& Bougie, 2013). In social and behavioral sciences researches, $\mathrm{R} 2$ value between $2 \%$ and $13 \%$ is considered as a small effect, a value between $13 \%$ and $26 \%$ is considered a medium effect, and a value above $26 \%$ is considered as a large effect (Ringle, Silva, \& Bido, 2015). Table 7 shows that the model explains the variation in SD and SWB to a large extent (R2>.26) (Ringle, Silva, \& Bido, 2015).

Table 7 - R2 values

\begin{tabular}{lc}
\multicolumn{1}{c}{ Construct } & \multicolumn{1}{c}{ R2 } \\
\hline SD & 0.292 \\
SWB & 0.562
\end{tabular}

Source: SmartPLS output of research data for this research.

3.2.4 R-square change and f-square size effect of exogenous factors

$\mathrm{R} 2$ change measures the difference in the model strength when an exogenous factor is removed from the model (Garson, 2016). It shows whether a model improves or becomes weak by the deletion of an exogenous factor. The f2 size effect, calculated through R2 change, 
determines the proportion of the unexplained variance accounted for by the $\mathrm{R} 2$ change. The higher the value of $\mathrm{f} 2$ size effect, the larger is the effect of that exogenous variable on the endogenous variable (Garson, 2016). This effect is small if the value is between 0.02 and 0.15 ; medium if it is between 0.15 and 0.35 , and high if it exceeds 0.35 (Garson, 2016). Shows that removing ITP from the model, will have a medium effect on SD $(.15<\mathrm{f} 2<.35)$; removing Patience will have a small effect on SD and SWB (f2<.15) However, removing SD will have a large effect on SWB (f2>.35) (Henseler, Hubona, \& Ray, 2016).

Table 8 - f2 size effect

\begin{tabular}{lll}
\hline Construct & SD & SWB \\
\hline ITP & 0.224 & \\
Patience & 0.126 & 0.042 \\
SD & & 0.926
\end{tabular}

Source: SmartPLS output of research data for this research.

Analysis of multiple dependency relationships concluded that the direct effect of intention to purchase on self-determination, and the effect of patience on self-determination, and the effect of self-determination on subjective well-being was large and significant. In contrast, the direct effect of patience on subjective well-being was moderately strong and significant. The analysis also showed that all the indirect effects of constructs in the model were significant.

The summarized results of hypothesis testing are presented in Table 9. 
Table 9: Summarized Results of Hypothesis Testing

\section{Hypothesis}

Accepted?

(Yes/No)

H1 Intention to purchase smartphones (ITP) has a positive impact on Yes subjective well-being (SWB) of BoP customer

H2 Intention to purchase smartphone (ITP) has a positive impact on self- $\quad$ Yes determination (SD)of BoP customer

H3 Self-determination (SD) has a positive impact on the subjective well- $\quad$ Yes being (SWB) of BoP customer

H4 Self-determination (SD) mediates the relationship between intention to Yes purchase (ITP) and subjective well-being (SWB) of BoP customer

H5 Patience has a positive impact on self-determination (SD) of BoP Yes customer

H6 Patience has a positive impact on subjective well-being (SWB) of BoP Yes customer

H7 Self-determination (SD) mediates the relationship between Patience and Yes subjective well-being (SWB) of BoP

Source: Hypotheses testing based on SmartPLS output of research data for this research.

\section{Discussion}

\subsection{Direct and indirect effects of intention to purchase smartphone on subjective well-being}

This research concluded that the intention to purchase smartphones had a significant direct effect on BoP customers' self-determination, which affected subjective well-being. By purchasing non-essential products, particularly smartphones, BoP customers improved their self-image to avoid social exclusion. Earlier research has established that non-essential purchases help BoP customers to conform to socially acceptable consumption practices that improve social comparison with those who are better off (Henriksen, Henriksson, \& Wadsten, 2018; Howell \& Hill, 2009). In other words, deprivations make such people aspire for products that enhance their self-image and gain them inclusion into a better-off social group (Mukherjee, Jebarajakirthy, \& Datta, 2020). In this way, they try to satisfy their psychological needs of autonomy and relatedness to others while gaining a sense of competence in managing their 
limited resources. That is why it is concluded that purchases of non-essential items, particularly smartphones, help improve the self-determination of BoP customers. Smartphones are seen as socially perceived necessity, they are being purchased by BoP customers to project their enhanced self-concept and escape poverty (Abor, Amidu, \& Issahaku, 2018; Aro \& Wilska, 2014). For this reason, consumption-deprived customers, at times, prefer to fulfill their life aspirations rather than fulfilling their basic needs, and by doing so, they try to regain control of their life (Cannon, Goldsmith, \& Roux, 2019).

It was established that intention to purchase smartphones increases the subjective wellbeing of marginalized consumers (Bartikowski, Laroche, Jamal, \& Yang, 2018). That is to say that such purchases help enhance one's self-concept and increase hedonic well-being (Sun, Wang, Xu, \& Jiang, 2019). Furthermore, such purchases also fulfil the need for regaining autonomy and self-esteem in BoP consumers, which in turn, increases their level of happiness (Moldes, Banerjee, Easterbrook, Harris, \& Dittmar, 2019). Therefore, these researches support the findings that non-essential purchases impact self-determination, and together they affect subjective well-being. In other words, self-determination needs mediate the relationship between intention to purchase smartphones and subjective well-being.

\subsection{Direct and indirect effects of patience on subjective well-being}

Findings of this research showed that patience had a significant direct impact on selfdetermination and subjective well-being. These findings are explained by reiterating that consumption-inadequate people are stereotyped as morally delinquent, frustrated, and unhappy in a consumer society. Due to resource constraints, BoP customers' autonomy over their circumstances is limited. According to self-determination theory, such constraints lower the subjective well-being of people. However, the findings of this research suggest that when a sense of lack of control over one's circumstances tends to lower one's subjective well-being, patience does not let that person despair. Hence patience affects self-determination and subjective well-being. This research suggests that BoP customers are survival-oriented, and for many respondents, self-determination stems from the necessity to survive hardships. Literature supports the finding that patience has a direct impact on goal achievement which, in turn, affects subjective well-being (Schnitker, 2012). Patience is similar to a secondary control that comes into effect when a person is unable to change his or her circumstances; therefore, it increases subjective well-being in the face of adversity (Schnitker, Houltberg, Dyrness, \& Redmond, 2017). 
The above finding is supported by extant literature. Earlier research suggested that people who did not conform to socially accepted consumption practices, experience negative stereotyping, and social exclusion (Hamilton, 2011). In other words, consumption-inadequate people are regarded as morally delinquent, frustrated, and unhappy. BoP customers intend to engage in socially desirable consumption practices to experience happiness and selfdetermination. Under economically challenging circumstances, where things mostly appear out of one's control, a BoP customer would purchase non-essential products that signal some status and power for that person, and would feel happy and satisfied (Martin \& Hill, 2015). In the context of a digital revolution, smartphones have made a gateway to the BoP population too. Purchasing a smartphone and accessing the internet through it give BoP customers a sense of social inclusion, self-determination, and subjective well-being (Pearce \& Rice, 2013). However, when a sense of lack of control over one's circumstances tends to lower one's happiness, patience acts as a control mechanism and does not let the person despair.

\subsection{Subjective well-being and marketing related issues of bop}

Back in 1995, research suggested that markets can restore a sense of wholeness for those who experience low levels of subjective well-being (Oropesa, 1995). It was suggested that economically challenged consumers, who were considered as flawed and unhappy customers because of their inability to engage in socially relevant consumption practices, bought products that reflected a better lifestyle, hence improving their sense of dignity, self-worth, and social identity (Jaikumar, Singh, \& Sarin, 2018; Martin \& Hill, 2012). In other words, such customers sought wholeness by turning towards conspicuous consumption (Mukherjee, Jebarajakirthy, \& Datta, 2020). Further, it was suggested that such people were market savvy despite being financially constrained (Jaikumar, Singh, \& Sarin, 2018). Implications of such BoP consumer behavior was reflected in a growth of second hand products and marketing firms responded by developing masstige brands. However, as literature suggests, marketers need to connect their value offering with the aspirational social identity of the BoP consumers. Such a consumer may not follow Maslow's hierarchy of needs and may engage in the satisfaction of higher order needs before adequate satisfaction of basic needs. Marketers can improve the symbolic appeal of their products and brands by segmenting the market on the basis of BoP aspirations. A relevant and successful examples is Xiomi smartphone in India which is targeting customers belonging to lower levels of socio economic pyramid (Srivastava, Mukherjee, \& Jebarajakirthy, 
2020). Furthermore, marketers can build marketing communications that focus on the fulfillment of social needs and psychological needs of self-determination for BoP segments.

\section{Theoretical implications}

Extant literature shows that social identity theory has been used to explain non-essential purchase behavior; the theory of self-determination has been used to explain the effect of selfdetermination on subjective well-being (Cannon, Goldsmith, \& Roux, 2019; Hamilton, et al., 2014; Henriksen, Henriksson, \& Wadsten, 2018; Martin \& Hill, 2015; Moldes, Banerjee, Easterbrook, Harris, \& Dittmar, 2019; Schnitker, 2012). The theoretical contribution of this analysis connected patience with social identity theory and self-determination theory. Relationships between intention to purchase, self-determination, and subjective well-being and patience were studied in this research. Patience's direct impact on self-determination and subjective well-being and indirect effect on subjective well-being were established to be significant. This research broadens the existing theoretical foundations of discretionary purchase behavior of the bottom of pyramid customers. It shows that lack of autonomy affects subjective well-being; however, patience does not let a person despair. The concept of patience as a predictor of self-determination and subjective well-being was added to this model, and its influence was established to be significant (Hamilton, et al., 2014; Martin \& Hill, 2015; Yurdakul, Atik, \& Dholakia, 2017).

This research has made an academic contribution by explaining the role of patience in the relationship between poverty, self-determination, subjective wellbeing and attitude towards life, and by combining social identity theory with theory of self-determination. It highlighted that BoP consumers would purchase technological products like smartphones to fulfill their self-determination needs and to improve their subjective well-being. It also suggested that patience would help such a consumer in goal attainment and improving subjective wellbeing. This research also suggested that patience offered an antidote to immediate gratification attitude found in consumer culture.

\section{Managerial implications}

This research expands the existing body of knowledge about the value requirements of BoP people. It shows that they purchase non-essential goods to avoid poverty-related shame, project an improved self-image, manifest self-determination, and experience happiness. BoP population that is not living on welfare schemes is purchasing aspirational products. By doing 
so, it is addressing the deep inequalities of the social structure. Marketers will find these insights useful in designing more relevant value propositions for the bottom of pyramid customers. They can use this understanding to develop products that give BoP customers a sense of inclusion and satisfy their psychological needs for self-determination in a consumer society. Casual observation shows that despite limited means, BoP is engaging in non-essential purchases. Therefore, marketers can channelize spending on products that better fulfill the needs for social inclusion, self-determination, and subjective well-being.

\section{Social contribution}

BoP customers, at time spend their income on prohibited, illegal, or stigmatized products such as tobacco and alcohol, however, marketers should seek to provide products that become a part of the consumption basket consisting of 'the Six Ss' - subsistence, sound health, safety, sociality, sovereignty, and spirituality which are absolutely necessary for achieving the goal of overall human wellbeing (Jaiswal \& Gupta, 2015). The findings of this research hold social significance because given a choice, a BoP customer would purchase products that are neither prohibited nor illegal, and that help him or her in fulfilling his or her aspirations, and in this process, patience would not let that person despair.

\section{Future direction}

This research suggests that BoP customers buy non-essential products to enhance their self-determination and subjective well-being. When adverse situations tend to lower selfdetermination and subjective well-being, patience does not let a person despair. In future, patience could be studied further to find out when it manifests itself as a trait factor and when as a state factor for consumption-inadequate consumers. Further studies may be undertaken to test the moderating effect of self-determination and patience on the relationship between intention to purchase non-essential items and subjective well-being for BoP customers. Such studies will further investigate the role of self-determination and patience in the fulfillment of hedonic and material aspirations of BoP customers.

\section{References}


Abor, J. Y., Amidu, M., \& Issahaku, H. (2018). Mobile telephony, financial inclusion and inclusive growth. Journal of African Business, 19(3), 430-453. https://doi:10.1080/15228916.2017.1419332

Adkins, N. R., \& Ozanne, J. L. (2005). The low literate consumer. Journal of Consumer Research, 32(1), 93-105. https://doi:10.1086/429603

Alba, J. W., \& Williams, E. F. (2013). Pleasure principles: A review of research on hedonic consumption. Journal of Consumer Psychology, 23(1), 2-18.

https://doi:10.1016/j.jcps.2012.07.003

Alexander, C. S., \& Prasad, A. (2014). Bottom-up workplace law enforcement: An empirical analysis. Retrieved February 19, 2021, from http://ilj.law.indiana.edu/articles/8-AlexanderPrasad.pdf

Alkire, S., \& Santos, M. E. (2014). Measuring acute poverty in the developing world: Robustness and scope of the multidimensional poverty index. World Development, 59, 251-274.

Aro, R., \& Wilska, T.-A. (2014). Standard of living, consumption norms, and perceived necessities. International Journal of Sociology and Social Policy, 34(9/10) 710-728. https://doi:10.1108/ijssp-06-2013-0064

Atkin, D., Colson-Sihra, E., \& Shayo, M. (2019, February 02). How do we choose our identity? A revealed preference approach using food consumption. Retrieved February 10, 2021, from https://ideas.repec.org/p/nbr/nberwo/25693.html

Baishya, K., \& Samalia, H. V. (2020). Factors influencing smartphone adoption: A study in the Indian bottom of the pyramid context. Global Business Review, 21(6), 1387-1405. https://doi:10.1177/0972150919856961

Bartikowski, B., Laroche, M., Jamal, A., \& Yang, Z. (2018). The type-of-internet-access digital divide and the well-being of ethnic minority and majority consumers: A multicountry investigation. Journal of Business Research, 82, 373-380.

https://doi:10.1016/j.jbusres.2017.05.033

Beaton, D. E., Bombardier, C., Guillemin, F., \& Ferraz, M. B. (2000). Guidelines for the process of cross-cultural adaptation of self-report measures. Spine, 25(24), 3186-3191. https://doi:10.1097/00007632-200012150-00014

Blocker, C. P., Ruth, J. A., Sridharan, S., Beckwith, C., Ekici, A., Goudie-Hutton, M., . . . Varman, R. (2013). Understanding poverty and promoting poverty alleviation through transformative consumer research. Journal of Business Research, 66(8), 1195-1202. https://doi:10.1016/j.jbusres.2012.08.012

Brown, K. W., Kasser, T., Ryan, R. M., \& Konow, J. (2016). Materialism, spending, and affect: an event-sampling study of marketplace behavior and its affective costs. Journal of Happiness Studies, 17(6), 2277-2292. https://doi:10.1007/s10902-015-9694-9 
Bülbül, A. E., \& Arslan, C. (2017). Investigation of patience tendency levels in terms of selfdetermination, self-compassion and personality features. Universal Journal of Educational Research, 5(9), 1632-1645. https://doi:10.13189/ujer.2017.050921

Butt, A. R. (2020, February 26). Second-hand mobile sale-purchase business complete guide. Retrieved February 08, 2021, from https://www.phoneworld.com.pk/second-hand-mobilesale-purchase-business/

Cannon, C., Goldsmith, K., \& Roux, C. (2019). A self-regulatory model of resource scarcity. Journal of Consumer Psychology, 29(1), 104-127. https://doi:10.1002/jcpy.1035

Chen, Y., Yao, M., \& Yan, W. (2014). Materialism and well-being among Chinese college students: The mediating role of basic psychological need satisfaction. Journal of Health Psychology, 19(10), 1232-1240. https://doi:10.1177/1359105313488973

Chikweche, T., \& Fletcher, R. (2012). Undertaking research at the bottom of the pyramid using qualitative methods. Qualitative Market Research: An International Journal, 15(3), 242-267. https://doi:10.1108/13522751211231978

Chmielewski, D. A., Dembek, K., \& Beckett, J. R. (2018). 'Business Unusual': Building BoP 3.0. Journal of Business Ethics, 161(1), 211-229. https://doi:10.1007/s10551-018-3938-7

Cho, E., \& Kim, S. (2014). Cronbach's coefficient alpha. Organizational Research Methods, 18(2), 207-230. https://doi:10.1177/1094428114555994

Dahana, W. D., Kobayashi, T., \& Ebisuya, A. (2018). Empirical study of heterogeneous behavior at the base of the pyramid: The influence of demographic and psychographic factors. Journal of International Consumer Marketing, 30(3), 173-191. https://doi:10.1080/08961530.2017.1399308

Diener, E., Emmons, R. A., Larsen, R. J., \& Griffin, S. (1985). The satisfaction with life scale. Journal of Personality Assessment, 49, 71-75.

Diener, E., Oishi, S., \& Lucas, R. E. (2015). National accounts of subjective well-being. American Psychologist, 70(3), 234-242. https://doi:10.1037/a0038899

Epstein, J., Santo, R. M., \& Guillemin, F. (2015). A review of guidelines for cross-cultural adaptation of questionnaires could not bring out a consensus. Journal of Clinical Epidemiology, 68(4), 435-441. https://doi:10.1016/j.jclinepi.2014.11.021

Farooq, M. (2019, February 06). Active social media users in Pakistan grow by 5.7\%: Report. Retrieved February 10, 2021, from https://profit.pakistantoday.com.pk/2019/02/05/activesocial-media-users-in-pakistan-grow-by-5-7-report/

Fornell, C., \& Larcker, D. F. (1981). Evaluating structural equation models with unobservable variables and measurement error. Journal of Marketing Research, 18(1), 39-50.

Garrette, B., \& Karnani, A. (2010). Challenges in marketing socially useful goods to the poor. California Management Review, 52(4), 29-47. https://doi:10.1525/cmr.2010.52.4.29 
Garson, D. (2016). Partial least squares regression and structural equation ... Retrieved February 19, 2021, from https://www.amazon.com/Partial-Squares-Regression-StructuralEquation-ebook/dp/B00IC5DLHE

Greco, L. M., O'Boyle, E. H., Cockburn, B. S., \& Yuan, Z. (2017). Meta-analysis of coefficient alpha: A reliability generalization study. Journal of Management Studies, 55(4), 583-618. doi:10.1111/joms. 12328

Gupta, S., \& Srivastav, P. (2015). An exploratory investigation of aspirational consumption at the bottom of the pyramid. Journal of International Consumer Marketing, 28(1), 2-15. https://doi:10.1080/08961530.2015.1055873

Hair, J. F., Black, W. C., Babin, B. J., Anderson, R. E., \& Tatham, R. L. (2006). Multivariate data analysis (6th ed.). Upper Saddle River, NJ: Pearson University Press.

Hair, J. F., Gabriel, M., \& Patel, V. (2014). AMOS covariance-based structural equation modeling (CB-SEM): Guidelines on its application as a marketing research tool. Brazilian Journal of Marketing, 13(2). https://doi:10.5585/remark.v13i2.2718

Hair, J. J., Sarstedt, M., Hopkins, L., \& Kuppelwieser, V. G. (2014). Partial least squares structural equation modeling (PLS-SEM). European Business Review, 26(2), 106-121. https://doi:10.1108/ebr-10-2013-0128

Hamilton, K. (2011). Low-income families and coping through brands: Inclusion or stigma? Sociology, 46(1), 74-90. https://doi:10.1177/0038038511416146

Hamilton, K., Piacentini, M. G., Banister, E., Barrios, A., Blocker, C. P., Coleman, C. A., . . . Saatcioglu, B. (2014). Poverty in consumer culture: Towards a transformative social representation. Journal of Marketing Management, 30(17-18), 1833-1857. https://doi:10.1080/0267257x.2014.967929

Haybron, D. M. (2016). The philosophical basis of eudaimonic psychology. Retrieved February 19, 2021, from https://www.researchgate.net/publication/309279545_The_Philosophical_Basis_of_Eudaim onic_Psychology

Henriksen, J., Henriksson, P., \& Wadsten, L. (2018). We are what we buy - semantic scholar. Retrieved February 19, 2021, from https://pdfs.semanticscholar.org/7cca/cc2aca38b03c3600bf38758be99099bde6fc.pdf

Henseler, J., Fassott, G., Dijkstra, T. K., \& Wilson, B. (2012). Analysing quadratic effects of formative constructs by means of variance-based structural equation modelling. European Journal of Information Systems, 21(1), 99-112. https://doi:10.1057/ejis.2011.36

Henseler, J., Hubona, G., \& Ray, P. A. (2016). Using PLS path modeling in new technology research: Updated guidelines. Industrial Management \& Data Systems, 116(1), 2-20. https://doi:10.1108/imds-09-2015-0382 
Hill, R. P. (2018). Theory of marketplace morality and impoverished consumers. Marketing Theory, 18(3), 411-420. https://doi:10.1177/1470593117753983

Hill, R. P., Martin, K. D., \& Chaplin, L. N. (2012). A tale of two marketplaces: Consumption restriction, social comparison, and life satisfaction. Marketing Letters, 23(3), 731-744. https://doi:10.1007/s11002-012-9175-4

Howell, R. T., \& Hill, G. (2009). The mediators of experiential purchases: Determining the impact of psychological needs satisfaction and social comparison. The Journal of Positive Psychology, 4(6), 511-522. https://doi:10.1080/17439760903270993

Jafari, A., Dedeoğlu, A. Ö, Regany, F., Üstündağli, E., \& Batat, W. (2014). Rethinking religion in the context of ethnicity and well-being. Marketing Theory, 15(2), 287-295. https://doi:10.1177/1470593114553329

Jaikumar, S., Singh, R., \& Sarin, A. (2018). 'I show off, so I am well off': Subjective economic well-being and conspicuous consumption in an emerging economy. Journal of Business Research, 86, 386-393. https://doi:10.1016/j.jbusres.2017.05.027

Jaiswal, A. K., \& Gupta, S. (2015). The influence of marketing on consumption behavior at the bottom of the pyramid. Journal of Consumer Marketing, 32(2), 113-124. https://doi:10.1108/jcm-05-2014-0996

Javed, K., \& Awan, M. S. (2020). Spatial and gender based comparison of Multidimensional Poverty: Household level analysis from Pakistan. Retrieved February 20, 2021, from http://european-science.com/eojnss/article/view/5916/pdf

Kock, N., \& Hadaya, P. (2016). Minimum sample size estimation In PLS-SEM: The inverse square root and Gamma-exponential methods. Information Systems Journal, 28(1), 227 261. https://doi:10.1111/isj.12131

Martin, K. D., \& Hill, R. P. (2012). Life satisfaction, self-determination, and consumption Adequacy at the bottom of the pyramid. Journal of Consumer Research, 38(6), 1155-1168. https://doi:10.1086/661528

Martin, K. D., \& Hill, R. P. (2015). Saving and well-being at the base of the pyramid. Journal of Service Research, 18(3), 405-421. https://doi:10.1177/1094670514563496

Matthews, L., Hair, J., \& Matthews, R. (2018, January 01). PLS-SEM: The holy grail for advanced analysis. Retrieved February 20, 2021, from https://www.semanticscholar.org/paper/PLS-SEM-\%3A-THE-HOLY-GRAIL-FORADVANCED-ANALYSIS-Matthews/d7d8fe1725b2326e0c70d50604930fd6fadbdfb6

Mitlin, D., \& Satterthwaite, D. (2013). Urban poverty in the global south: Scale and nature. Retrieved February 20, 2021, from https://www.routledge.com/Urban-Poverty-in-theGlobal-South-Scale-and-Nature/Mitlin-Satterthwaite/p/book/9780415624671

Moldes, O., Banerjee, R., Easterbrook, M. J., Harris, P. R., \& Dittmar, H. (2019). Identity changes and well-being gains of spending money on material and experiential consumer 
products. Journal of Economic Psychology, 72, 229-244. https://doi:10.1016/j.joep.2019.04.003

Mukherjee, S., Jebarajakirthy, C., \& Datta, B. (2020). Retailer selection compulsion in the subsistence markets. Journal of Retailing and Consumer Services, 52, 101904. https://doi:10.1016/j.jretconser.2019.101904

Okeleke, K. (2019). The power of mobile to accelerate digital transformation ... Retrieved February 20, 2021, from https://www.gsma.com/mobilefordevelopment/wpcontent/uploads/2019/10/The-Power-of-Mobile-to-Accelerate-Digital-Transformation-inPakistan-2019.pdf

Oropesa, R. S. (1995). Consumer possessions, consumer passions, and subjective well-being. Sociological Forum, 10(2), 215-244. https://doi:10.1007/bf02095959

Papagiannidis, S., Bourlakis, M., Alamanos, E., \& Dennis, C. (2017, April 12). Preferences of smart shopping channels and their impact on perceived wellbeing and social inclusion. Retrieved February 20, 2021, from https://www.sciencedirect.com/science/article/abs/pii/S0747563217302716

Pathak, A., Sharma, S., Heinemann, A. W., Stratford, P. W., Ribeiro, D. C., \& Abbott, J. H. (2020). Development and assessment of a verbal Response scale for the patient-specific functional scale (PSFS) in a low-literacy, non-western population. Quality of Life Research, 30(2), 613-628. https://doi:10.1007/s11136-020-02640-0

Pearce, K. E., \& Rice, R. E. (2013). Digital divides from access to activities: Comparing mobile and personal computer internet users. Journal of Communication, 63(4), 721-744. https://doi:10.1111/jcom.12045

Prahalad, D. (2019, January 02). The new fortune at the bottom of the pyramid. Retrieved February 20, 2021, from https://www.strategy-business.com/article/The-New-Fortune-atthe-Bottom-of-the-Pyramid

Richins, M. L. (2004). The material values scale: Measurement properties and development of a short form. Journal of Consumer Research, 31(1), 209-219. https://doi:10.1086/383436

Ringle, C., Silva, D. D., \& Bido, D. (2015). Structural equation modeling with the SmartPLS. Brazilian Journal Of Marketing, 13(2). https://doi:10.5585/remark.v13i2.2717

Ryan, R. M., \& Deci, E. L. (2000). Self-determination theory and the facilitation of intrinsic motivation, social development, and well-being. American Psychologist, 55(1), 68-78. https://doi:10.1037/0003-066x.55.1.68

Sarstedt, M., Ringle, C. M., \& Hair, J. F. (2017). Partial least squares structural equation modeling. Handbook of Market Research, 1-40. https://doi:10.1007/978-3-319-05542$8 \_15-1$

Schnitker, S. A. (2012). An examination of patience and well-being. The Journal of Positive Psychology, 7(4), 263-280. https://doi:10.1080/17439760.2012.697185 
Schnitker, S. A., Houltberg, B., Dyrness, W., \& Redmond, N. (2017). The virtue of patience, spirituality, and suffering: Integrating lessons from positive psychology, psychology of religion, and Christian theology. Psychology of Religion and Spirituality, 9(3), 264-275. https://doi:10.1037/rel0000099

Sekaran, U., \& Bourgie, R. (2013). Research methods for business: A skill-building approach. Chichester, West Sussex: Wiley.

Sharma, Y., \& Nasreen, R. (2017). Perceived consumer-centric Marketing-Mix at the urban ... Retrieved February 20, 2021, from

https://www.researchgate.net/publication/320009387_Perceived_Consumer-

Centric_Marketing-Mix_at_the_Urban_Bottom_of_the_Pyramid-

An_empirical_study_of_Food_market

Srivastava, A., Mukherjee, S., \& Jebarajakirthy, C. (2020). Aspirational consumption at the bottom of pyramid: A review of literature and future research directions. Journal of Business Research, 110, 246-259. https://doi:10.1016/j.jbusres.2019.12.045

Stets, J. E., \& Serpe, R. T. (2013). Identity theory. In J. E. Stets, \& R. T. Serpe, Handbook of social psychology (pp. 31-60). Dordrecht, Netherlands: Springer.

Sun, Y., Wang, R., Xu, Y., \& Jiang, J. (2019). Will recalling a purchase increase your wellbeing? The sequential mediating roles of postpurchase sharing and relatedness need satisfaction. Asian Journal of Social Psychology, 22(4), 391-400.

https://doi:10.1111/ajsp.12382

United Nations Development Programme. (2008, July). Creating value for all: Strategies for doing business with the poor. Retrieved February 10, 2021, from https://www.undp.org/content/dam/rwanda/docs/povred/RW_rp_Creating_Value_for_All_ Doing_Business_with_the_Poor.pdf

Wang, R., Liu, H., Jiang, J., \& Song, Y. (2017). Will materialism lead to happiness? A longitudinal analysis of the mediating role of psychological needs satisfaction. Personality and Individual Differences, 105, 312-317. https://doi:10.1016/j.paid.2016.10.014

Wieland, A., Durach, C. F., Kembro, J., \& Treiblmaier, H. (2017). Statistical and judgmental criteria for scale purification. Supply Chain Management: An International Journal, 22(4), 321-328. https://doi:10.1108/scm-07-2016-0230

World Bank Development Research Group. (2017). Retrieved September 19, 2017, from World Bank Development Research Group: https://data.worldbank.org/indicator/SI.POV.DDAY

Yu, H., Zhang, R., \& Liu, B. (2018). Analysis on consumers' purchase and shopping wellbeing in online shopping Carnivals with Two motivational dimensions. Sustainability, 10(12), 4603. https://doi:10.3390/su10124603 
Yu, S., Levesque-Bristol, C., \& Maeda, Y. (2017). General need for autonomy and subjective well-being: A meta-analysis of studies in the US and East Asia. Journal of Happiness Studies, 19(6), 1863-1882. https://doi:10.1007/s10902-017-9898-2

Yurdakul, D., Atik, D., \& Dholakia, N. (2017). Redefining the bottom of the pyramid from a marketing perspective. Marketing Theory, 17(3), 289-303.

https://doi:10.1177/1470593117704265

Zikmund, W. G., Babin, B. J., Carr, J. C., \& Griffin, M. (2013). Business research methods. Mason, Ohio: Cengage Learning. 